\title{
A combined protocol with piroxicam, chemotherapy, and whole pelvic irradiation with simultaneous boost volumetric modulated arc radiotherapy for muscle-invasive canine urinary transitional cell carcinoma: First clinical experience
}

\author{
Luca MALFASSI ${ }^{1) *}$, Francesca FIDANZIO ${ }^{3)}$, Massimo SALA ${ }^{11}$, Silvia MARCARINI ${ }^{1)}$, \\ Giovanni MAZZA ${ }^{1)}$, Nancy CARRARA ${ }^{1)}$, Simone PAVESI ${ }^{1}$, Giacomo GNUDI ${ }^{3)}$, \\ Gaetano URSO $^{2)}$ and Mario DOLERA ${ }^{1)}$ \\ 1)"La Cittadina" Foundation for Veterinary Studies and Research, Road to the "La cittadina", 26014, \\ Romanengo $(\mathrm{Cr})$, Italy \\ ${ }^{2)}$ Medical Physics Department, Local Health Authority of Lodi, A. Fleming 1 road, 26841, Casalpusterlengo (Lo), Italy \\ ${ }^{3)}$ Department of Veterinary Medical Science, University of Parma, Taglio 8 road, 43100, Parma, Italy
}

J. Vet. Med. Sci.

83(4): 695-704, 2021

doi: 10.1292/jvms.19-0662

Received: 17 December 2019 Accepted: 31 August 2020 Advanced Epub:

22 September 2020
ABSTRACT. The aims of this pilot study were to evaluate the feasibility and efficacy of high-dose hypofractionated volumetric modulated arc radiotherapy (VMAT) applied to whole pelvic region radiotherapy (WPRT) with multilevel simultaneous integrated boost (MLSIB) combined with piroxicam and chemotherapy for the treatment of canine transitional cell carcinoma (TCC) of the lower urinary tract with muscle invasion TCC. Twelve dogs were enrolled, according to stage, in two groups: group 1 , TCC confined to the urinary tract; group 2, TCC with metastasis. The planning target volume dose was tailored from 36 to $42 \mathrm{~Gy}$ in 6 fractions. All dogs were prescribed piroxicam and radiosensitizing carboplatin, and six received chemotherapy after radiotherapy. Serial follow-ups with computed tomography and magnetic resonance imaging were performed. Disease control and toxicity effects were evaluated according to the Response Evaluation Criteria in Solid Tumors and Veterinary Radiation Therapy Oncology Group criteria. The treatment was well tolerated, and no high-grade side effects were reported. The median overall survival times for groups 1 and 2 were 1,230 and 150 days, respectively. A considerable percentage of patients in group1 $(50 \%)$ were still alive at the time of writing this paper, and a longer follow-up could enable a more accurate survival analysis. This preliminary analysis shows that VMAT applied to the WPRT with MLSIB is an effective and safe option for dogs with lower urinary TCC, although the presence of metastases worsens the prognosis.

KEYWORDS: chemotherapy, dog, piroxicam, radiotherapy, transitional cell carcinoma

Transitional cell carcinoma (TCC) is the most common cancer of the canine urinary tract, accounting for $<2 \%$ of canine malignant tumors [26, 34-36, 54, 57]. According to the World Health Organization (WHO) criteria for staging canine bladder tumors [60], 78\% of dogs with TCC have been reported to have T2 tumors (invading the bladder wall, i.e., muscle-invasive), and 20\% have T3 tumors (invading neighboring organs) $[26,36,61]$; papillary lesions and a thickened bladder wall are frequent features that can lead to partial or complete urinary tract obstruction [75]. In male canines, the prostate gland may also be involved [41].

Dogs with invasive TCC have different treatment options, including cyclooxygenase (COX) inhibitors (e.g., piroxicam, deracoxib, and pirocoxib) $[26,32,34-36,38,39,57,63]$, cytotoxic chemotherapy drugs (cisplatin, carboplatin, mitoxantrone, vinblastine, gemcitabine) [1, 19, 26, 28, 34-36, 39, 54], metronomic chemotherapy (chlorambucil) [13, 20, 23, 24, 47-49, 64, 68, 69], laser ablation $[14,26,43]$, urethral or ureteral stent placement $[9,26,52,74]$, surgery $[11,26,29,34,35,50,54,66,67,70,76,77]$, and other radiation therapy protocols $[55,56,62,73]$; however, a single treatment that leads to a robust response is lacking.

Piroxicam is a single agent that is generally well tolerated in palliative treatment [38], and lifelong use is recommended, even with complete remission [63]. Treatment is discontinued if progressive disease or unacceptable toxicity is noted. 
Because of the typical trigonal location and the urethral involvement of the tumor, complete surgical excision of the TCC is not usually possible [63]. Moreover, many dogs develop multifocal TCC in the bladder. In patients where the tumor is located at the apex of the bladder, partial cystectomy is an option [29,71]. Additionally, surgery can be used as a palliative procedure for debulking inoperable tumors in dogs with distal urinary tract obstruction [14].

Despite the high rate of metastasis in canine TCC, progression of local disease is the cause of death for many dogs in which the primary tumor is not adequately controlled [35], demonstrating the need for a combined approach for both local and systemic treatments.

The standard radiotherapy (RT) for lower urinary tract malignancies in humans is whole pelvic region radiotherapy (WPRT) [12, $15,25]$. The rationale for this treatment is to limit the progression of the disease to the lymphatics and neighboring organs. Studies on RT in canine TCC using conventional techniques are limited because of the difficulty in treating many targets simultaneously $[2-4,6,10,12,14,15,18,25-27,34,36-39,42,48,51,53,56,60,62,71,73]$, and no extensive studies have been devoted to WPRT. Using the 3D conformal conventional techniques of RT for the lower urinary tract TCC poses a challenge in dose escalation trials and often results in induced sub-optimal outcomes as TCC is often locally advanced at the time of diagnosis. Moreover, daily variation in the position and dimension of the abdominal organs, especially for the bladder, suggests an increase in target margins in the planning target volume (PTV) definition with unwanted dosages to the surrounding healthy organs, toxicity, and unexpected results [3-5]. Complications of normal pelvic tissue irradiation with $3 \mathrm{D}$ conformal radiotherapy and the difficulty of targeting the treatment volumes are the major limiting factors for treating canine TCC patients with hypofractionated radiation [3, 25, 48]. The side effects reported in the literature for conformal 3D radiotherapy for TCC treatments include pollakiuria, urinary incontinence, cystitis, stranguria, and hydronephrosis $[3,12,15,25,48,53]$. Additionally, a tumor near the urethral orifice may result in bladder outlet obstruction and urinary retention. Other infrequent clinical signs include lameness caused by bone metastasis [16].

Based on these considerations, this pilot study was performed to evaluate the feasibility and effectiveness of a combined treatment with piroxicam and chemoradiotherapy for overcoming the technical difficulties of standard 3D conformal radiotherapy through volumetric modulated arc radiotherapy (VMAT) in hypofractionated dose regimens and with multilevel simultaneous integrated boost (MLSIB) characterized by different dose levels for the whole pelvic region irradiation and tumor volumes.

\section{MATERIALS AND METHODS}

The pilot study and the radiotherapy (RT) treatment protocol were approved by the local scientific ethics committee (date, November28, 2013; record number 07/2013). Dogs were recruited from 2013 to 2018, and the follow-up lasted until the time of writing the paper. All enrolled patients underwent a preliminary clinical examination and a complete blood count (CBC), serum biochemical profile, urinalysis, and ultrasound imaging [50] were performed in addition to histologic confirmation of the diagnosis of TCC/urothelial carcinoma.

Animals were anesthetized for diagnostic investigations, and midazolam (Istituto Biochimico Italiano Giovanni Lorenzini S.p.A., Aprilia, Italy) was used as premedication. All dogs underwent endotracheal intubation and were ventilated with Vetflurane isoflurane (Virbac Italia s.r.l., Milan, Italy) in mixed medical grade air and oxygen, with continuous monitoring of vital signs.

Based on imaging, the tumor was diagnosed and staged in agreement with the Clinical Staging System of the WHO [60].

Complete staging of the tumor was obtained with Brilliance 64 Slice computed tomography (CT) [58] (Philips Medical Systems, Amsterdam, the Netherlands) and/or Intera 1.5Tmagnetic resonance imaging (MRI) (Philips Medical Systems).

Total body CT scans were acquired before and after the injection of $300 \mathrm{mmol} / \mathrm{ml}$ contrast iodinated medium administered at a dose of $2 \mathrm{ml} / \mathrm{kg}$ iopamidol (Bracco, Milan, Italy). CT was used to evaluate the involvement of the urinary tract, to identify the involvement of the tributary or distal lymph nodes, and to detect the eventual presence of metastasis.

Patients were grouped into two groups: group 1 included dogs with tumors confined to the urinary tract; group 2 included dogs with lymph node involvement and/or metastasis. Any concomitant disease was registered.

In all dogs, therapy with piroxicam oral capsule $[27,31,38,62,73]$ (Mepha Pharma AG, Aesch, Switzerland) at $0.3 \mathrm{mg} / \mathrm{kg}$ once a day was prescribed after the staging.

All dogs except one received carboplatin therapy during irradiation $[17,44,46]$. The basic requirements for chemotherapy were as follows: absence of comorbidity, adequate medullary reserve, and absence of renal dysfunction.

Carboplatin (Teva Pharmaceutical Industries, Petah Tikva, Israel) was administered at a dose of $25 \mathrm{mg} / \mathrm{m}^{2}$ as a radiosensitizer [7, 12, 24] before each radiotherapy treatment. Carboplatin chemotherapy and cyclophosphamide (Baxter International Inc., Deerfield, IL, USA) metronomic chemotherapy [13, 20, 23, 24, 47, 48, 68, 69], as defined by the National Cancer Institute in its dictionary, at doses of $75 \mathrm{mg} / \mathrm{m}^{2} /$ week and $10 \mathrm{mg} / \mathrm{m}^{2} /$ day, respectively, were proposed to all dog owners after the end of the radiotherapy course, but only six people accepted it.

WPRT with MLSIB was performed. Volume treatment definitions included tumors with appropriate margins (PTV-tumor), lymphatic nodes (PTV-lymphatics), the entire bladder (PTV-bladder), the prostate and urethra (PTV-urethra), and the entire pelvis except the rectal volume (PTV-pelvis).

The PTV-tumor was determined by adding the volume of probable tissue invasion and the internal and setup margins to the tumor mass. The primary organs at risk (OAR) that were contoured were the colon and rectum, spinal cord and cauda equina, small bowel, and hip joints.

RT treatment was administered using a 6-MV photon beam with a SynergyS (Elekta Instrument AB, Stockholm, Sweden) linear accelerator (LINAC) equipped with a micromultileaf beam collimator (Elekta Beam Modulator) and an XVI cone-beam computed 
tomography (CBCT) system. VMAT treatments were planned with the Elekta CMS Monaco treatment planning system (TPS) and a

Monte Carlo statistical algorithm.

The internal protocol for the radiotherapy treatment was based on the following [21]:

- Use of a customized repositioning device made with a homemade cradle and an indexing system for the CT and LINAC couch. For all patients, preliminary CT scans were performed to evaluate the best treatment setup. In particular, to optimize the dose distribution, each dog was scanned in lateral, dorsal, and sternal recumbency to study the displacement of the OAR and the target. In the CT simulation, the bladder was manually emptied and subsequently filled with customized saline solution.

- Two-step virtual simulation. Three radiopaque markers were embedded in the cradle, roughly defining the target isocenter position (setup reference point) in the first virtual simulation step. Second, after the target was contoured, the real target isocenter was identified, and a set of shifts from the setup reference point was calculated for the correct LINAC positioning procedure.

Customized treatment plan elaboration with defined dose constraints for all patients

The PTV coverage was considered acceptable for $\mathrm{V}_{95 \%}$ and $\mathrm{V}_{107 \%}$ levels (PTV volume receiving less than 95\% and more than $107 \%$ of the prescribed dose, respectively) of less than $5 \%$ and $1 \%$. Accordingly, the heterogeneity index (HI), defined as the ratio between the dose delivered to the hottest $5 \%$ of the tissue $\left(D_{5}\right)$ and the minimum dose received by $95 \%$ of the tissue $\left(D_{95}\right)$, was considered satisfactory when less than 1.12. The OAR dose constraints were roughly derived from human studies (human percentages or total volume cannot simply be adapted), as described by the American Association of Physicists [8] in Medicine Task Group 101 because no specific dose constraints have been reported in the veterinary literature. Ultimately, constraints were iteratively lowered during the elaboration of the plan while preserving the target coverage unless otherwise specified by the veterinarian.

\section{Pretreatment feasibility analysis}

A per-patient agreement between the planned and delivered doses was performed before the beginning of each treatment using the Delta4 (Scandidos, Uppsala, Sweden) system and the gamma function [45] (dose agreement of 3\% and a distance to agreement of $3 \mathrm{~mm})$.

\section{Setup error evaluation}

Each treatment session began with a CBCT acquired through the Elekta XVI system. The obtained scan and the planning CT were compared, and the shifts were analyzed as previously described [21]. If agreement was not achieved, the whole treatment procedure was repeated starting from the CT simulation. All shifts were registered and analyzed to provide feedback on setup reproducibility and repositioning device effectiveness.

All patients were treated at approximately the same time of the day. Our preparation protocol was similar to that reported in the literature [56]. Briefly, meals of equal quantity were withheld $8 \mathrm{hr}$ before each radiotherapy session, and defecation and urination were encouraged by walking prior to sedation. If the bladder size was significantly smaller at the pretreatment CBCT than the simulation CT, intravenous fluid therapy was used to restore the proper bladder volume. The filling difference was accepted within $2 \mathrm{~mm}$ along the major axis of the bladder. Because of variable patient and bladder size in relation to the target margin, there was no standard intravenous fluid bolus volume. In contrast, if the bladder size exceeded the amount planned, urethral catheterization or gentle manual expression of the urinary bladder was performed. In both cases, it was necessary to use CBCT to verify the correct positioning of the patient and the bladder dimensions after the operations.

The prescribed dose ranged from 36 to 42 Gy in six fractions, three times a week, depending on the body condition score and according to OAR proximity and dose tolerance. The equivalent total dose for fractions of 2 Gy (EQD2) was between 63.3 and 81.9 Gy using a tumor alpha/beta ratio of 3.27, as reported by Parfitt et al. [48].

Regular clinical examinations were performed during and after RT. Since dogs with TCC are at increased risk of contracting secondary bacterial infections, urinalysis and urine culture were performed periodically, while CBC and serum biochemical profiles were steadily evaluated in patients who received chemotherapy. Particular attention was devoted to the analysis of the quality of life in terms of return to urination in obstructed patients. Serial CT and MRI examinations were performed 2, 4, and 8 months after the end of RT and then according to clinical requests. The diagnostic imaging protocol for follow-up examinations consisted of repetition of one of the imaging techniques (CT or MRI), with the same scanning parameters used for the diagnostic exam and the same degree of bladder distension. Thickness, alterations in the organ wall, and neoplasm extension were adopted to evaluate the tumor variation and response according to the Response Evaluation Criteria in Solid Tumor (RECIST) [22] categorization and implemented with clinical follow-up examinations. Radiation toxicity was evaluated clinically and graded according to the Veterinary Radiation Therapy Oncology Group (VRTOG) [40] criteria.

Overall survival time (OST) and local progression-free survival (PFS) were estimated using the Kaplan-Meier [33] curve analysis method for the two patient groups and for all the patients kept together. All deaths and the progression of local disease were considered as events for OST and PFS, respectively. The median OST and 95\% confidence interval (CI) were calculated considering the time to the event from the end of radiation therapy and the differences in OST and PFS between the two groups, and the whole set of data was statistically analyzed using a log-rank test.

\section{RESULTS}

In total, 12dogs with lower urinary tract TCC were included in the study: 6 intact males, 1 neutered male, 3 intact females, and 2 spayed females, with a median age of 11 years (mean, 11 years; range, 8-13 years). Presenting complaints were typically hematuria 
and pollakiuria; dogs with urethral obstruction had dysuria, while dogs with metastasis showed pelvic pain.

Breed stratification and main clinical information are reported in Table 1. There was heterogeneous localization of neoplasms. In two dogs, surgical biopsy was performed before irradiation due to apex and ventral wall localization.

According to the criteria from the WHO [60], eight dogs were classified as T2N0M0 (group 1), while four dogs were classified as T3N1M1 (group 2).

At the time of diagnostic CT, the median PTV-tumor was $55.1 \mathrm{~cm}^{3}$ (range, 3.2-329.7 $\mathrm{cm}^{3}$ ). The prescribed doses ranged from 36 to $42 \mathrm{~Gy}$ in all dogs, and the main plan elaboration data are summarized in Table 2. Almost all plans fulfilled the prescribed requests for both the target coverage and the OAR sparing since the median 95\% isodose volume coverage (V $\left.\mathrm{V}_{95 \%}\right)$ for the PTVtumor was $96 \%$ (range $94.7-99.5 \%$ ), the median $107 \%$ isodose volume excess coverage $\left(\mathrm{V}_{107 \%}\right)$ was $0.1 \%$ (range $0-2.1 \%$ ), the HI was 1.09 (range 1.07-1.11), and the median doses with their standard deviations for the colon and rectum were 11 Gy (range 1.2-29.4 Gy) and 23.8 Gy (range 7.4-34.9 Gy), respectively. In Figs. 1 and 2, the dose distribution and dose-volume histogram (DVH) are shown for a representative case. Additionally, the agreement between the planned and delivered doses resulted in a median value of $98 \%$ (range 95-99\%) and was considered satisfactory, while the analysis on setup accuracy showed good reproducibility of our homemade repositioning device with similar results to that reported earlier [21].

Table 1. Breed stratification and main clinical data

\begin{tabular}{|c|c|c|c|c|c|c|c|c|c|c|}
\hline Dog & Breed & $\begin{array}{l}\text { Age } \\
\text { (Years) }\end{array}$ & $\begin{array}{c}\text { Body } \\
\text { weight }(\mathrm{kg})\end{array}$ & Sex & Localization & Stage & $\begin{array}{l}\text { Tumor Volume } \\
\text { Pre-RT }\end{array}$ & $\begin{array}{l}\text { Tumor } \\
\text { response }\end{array}$ & $\begin{array}{l}\text { Survival } \\
\text { (Days) }\end{array}$ & Cause of death \\
\hline 1 & Crossbreed & 10 & 12 & $\mathrm{M}$ & Bladder & T2N0M0 & 57.40 & $\mathrm{CR}$ & 276 & $\begin{array}{l}\text { Refused treatment } \\
\text { (vertebral metastasis) }\end{array}$ \\
\hline 2 & Crossbreed & 13 & 24 & M & Bladder & T2N0M0 & 55.10 & PR & 355 & $\begin{array}{l}\text { Recurrence of tumor in } \\
\text { bladder and lymphatics } \\
\text { not treated }\end{array}$ \\
\hline 3 & Crossbreed & 13 & 29 & $\mathrm{~F}$ & $\begin{array}{l}\text { Bladder and } \\
\text { urethra }\end{array}$ & T2N0M0 & 64.90 & $\mathrm{CR}$ & 1,230 & Pulmonary disease \\
\hline 4 & Crossbreed & 13 & 8 & M & Bladder & T3N1M1 & 82.67 & PR & 264 & $\begin{array}{l}\text { Euthanized-vertebral } \\
\text { infiltration and } \\
\text { pulmonary mass }\end{array}$ \\
\hline 5 & Crossbreed & 12 & 9 & SF & $\begin{array}{l}\text { Bladder and } \\
\text { urethra }\end{array}$ & T2N0M0 & 35.53 & $\begin{array}{l}\text { No follow- } \\
\text { up }\end{array}$ & 238 & Euthanized \\
\hline 6 & $\begin{array}{l}\text { Cocker } \\
\text { Spaniel }\end{array}$ & 10 & 12 & SF & $\begin{array}{l}\text { Bladder and } \\
\text { urethra }\end{array}$ & T3N1M1 & 3.33 & PR & 209 & $\begin{array}{l}\text { Urinary tenesmus- } \\
\text { refused medical therapy }\end{array}$ \\
\hline 7 & Setter & 8 & 22 & M & Urethra Prostate & T3N1M1 & 51.75 & SD & 151 & $\begin{array}{l}\text { Difficulty in urination-- } \\
\text { refused medical therapy }\end{array}$ \\
\hline 8 & Crossbreed & 8 & 32 & NM & $\begin{array}{l}\text { Bladder, urethra, } \\
\text { and prostate }\end{array}$ & T3N1M1 & 83.50 & $\mathrm{PD}$ & 36 & Euthanized \\
\hline 9 & Toy Poodle & 13 & 11 & SF & Bladder & T2N0M0 & 14.02 & PR & & Alive \\
\hline 10 & $\begin{array}{l}\text { French } \\
\text { Bulldog }\end{array}$ & 10 & 13 & M & Bladder & T2N0M0 & 77.73 & $\mathrm{CR}$ & & Alive \\
\hline 11 & Border Collie & 11 & 22 & $\mathrm{~F}$ & Bladder & T2N0M0 & 29.72 & PR & & Alive \\
\hline 12 & Crossbreed & 12 & 12 & M & Bladder & T2N0M0 & 30.00 & $\mathrm{CR}$ & & Alive \\
\hline
\end{tabular}

M, male; F, female; SF, sterilized female; NM, neutered male. CR, complete response; PR, partial response; SD, stable disease; PD, progressive disease.

Table 2. Plan optimization results

\begin{tabular}{ccccccc}
\hline Dog & $\begin{array}{c}\text { PTV volume } \\
(\mathrm{cc})\end{array}$ & $\mathrm{V}_{95 \%}{ }^{\mathrm{PTV}}$ & $\mathrm{V}_{107 \%}{ }^{\mathrm{PTV}}$ & $\mathrm{HI}$ & $\begin{array}{c}\text { Mean dose rectum } \\
(\mathrm{Gy})\end{array}$ & $\begin{array}{c}\text { Mean dose colon } \\
(\mathrm{Gy})\end{array}$ \\
\hline 1 & 88.5 & 95.0 & 0.1 & 1.09 & 23.9 & 22.2 \\
2 & 55.1 & 95.2 & 0 & 1.07 & 31.3 & 38.2 \\
3 & 65.2 & 95.9 & 0 & 1.08 & 31.7 & 28.7 \\
4 & 36.7 & 96.0 & 0.1 & 1.09 & 34.9 & 37.5 \\
5 & 6.7 & 99.0 & 0 & 1.07 & 8.6 & 35.4 \\
6 & 77.9 & 96.4 & 0 & 1.09 & 7.4 & 22.7 \\
7 & 29.7 & 94.7 & 0.3 & 1.10 & 18.4 & 36.7 \\
8 & 30.0 & 95.2 & 0.1 & 1.11 & 10.4 & 40.6 \\
9 & 82.2 & 96.8 & 2.1 & 1.11 & 31.5 & 20.4 \\
10 & 3.2 & 99.5 & 0 & 1.07 & 30.7 & 34.5 \\
11 & 51.8 & 95.0 & 0.1 & 1.10 & 23.6 & 37.7 \\
12 & 329.7 & 97.2 & 0 & 1.07 & 8.1 & 33.3 \\
\hline
\end{tabular}

PTV, planning target volume; $\mathrm{V}_{95 \%}{ }^{\mathrm{PTV}}$, planning target volume receiving the $95 \%$ of prescription dose; $\mathrm{V}_{107 \%}{ }^{\text {PTV }}$ planning target volume receiving more than the $107 \%$ of prescription dose; HI, homogeneity index. 

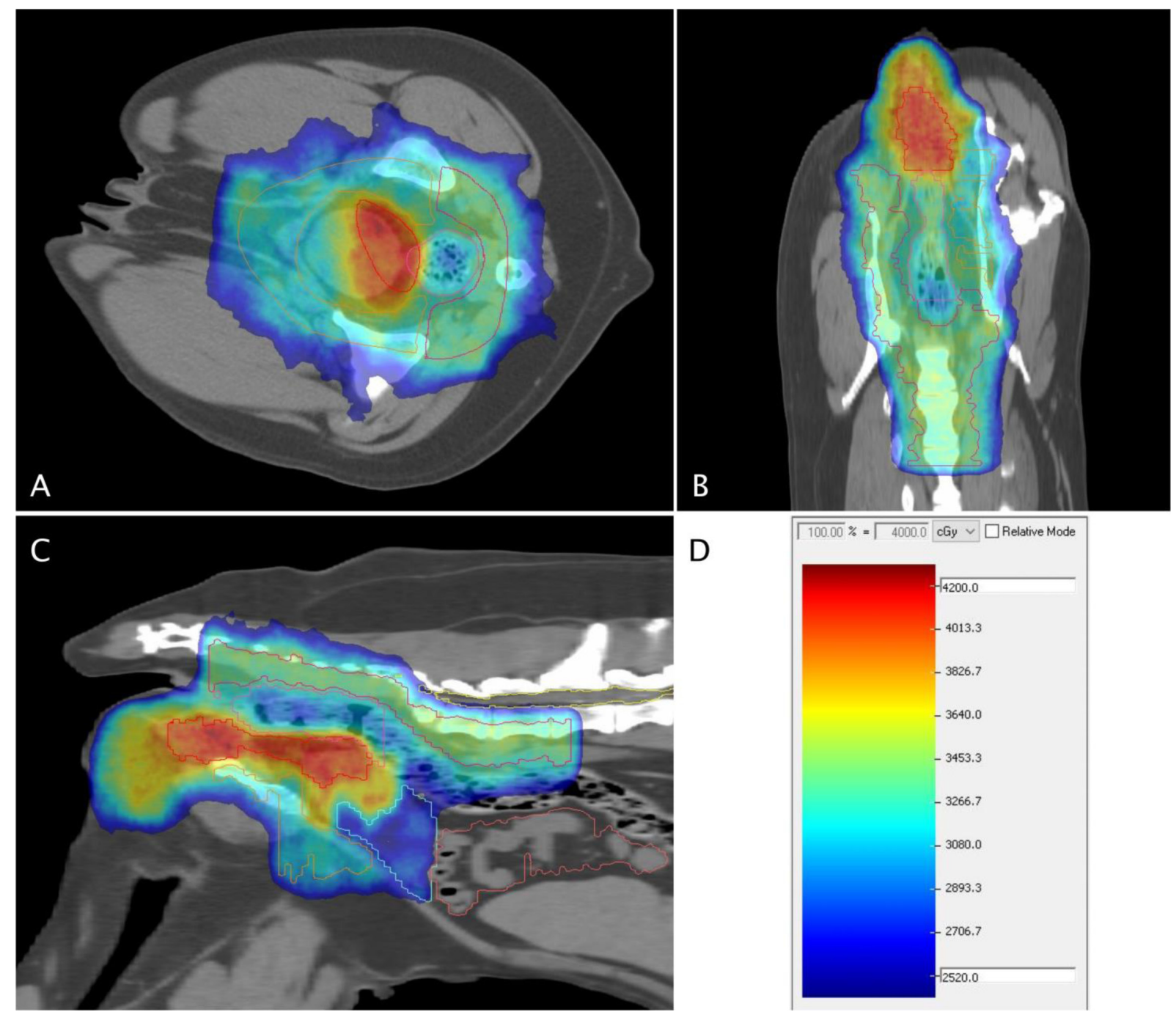

Fig. 1. Dose distribution of a representative case. (A) transversal projection; (B) coronal projection; (C) sagittal projection; (D) dose level distribution.

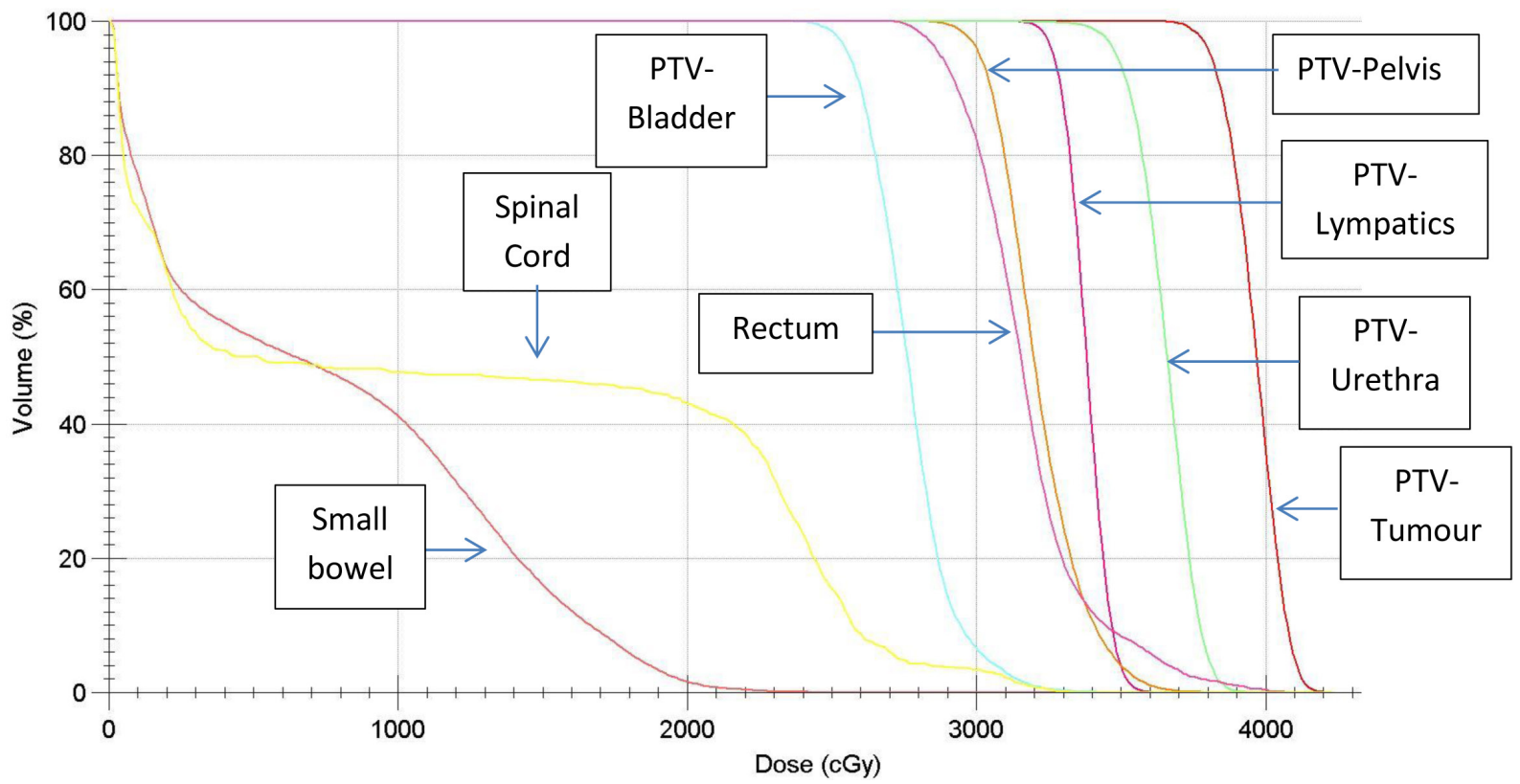

Fig. 2. Dose-volume histogram (DVH) of a representative case. 
After radiation therapy, six dogs were treated with chemotherapy: four dogs with carboplatin weekly (75 mg/m/week) and two dogs with metronomic cyclophosphamide. All dogs showed progressive shrinkage of the tumor during follow-up, as shown in Fig. 3, where volumes are shown at the diagnosis and two months after the end of radiotherapy for a typical case. According to RECIST, four dogs had a complete response (CR), five dogs had a partial response (PR), one dog had stable disease (SD), and one had progressive disease (PD) (Table 1). One patient was lost at the first follow-up, and we learned about the patient's death in the subsequent interview with the owner. After transient low-grade cystitis (VRTOG 1), there were no signs of adverse radiation effects on MRI or clinical examination in most patients, and the initial complaints were regressed.

At the time of data analysis, eight deaths were recorded, while four dogs that were still alive were censored in the Kaplan-Meier OST analysis, as shown in Fig. 4, where the OST results are reported for each of the patient groups separately and as a combined group. The median OST for groups 1 and 2 were 1,230 and 210 days, with a 95\% CI range of 1,230-1,230 and 116-302 days, respectively; the same data for the whole patient set included 360 days with a 95\% CI range of 229-481 days. Since there were an equal number of events and censored data in group 1, the median and range values had limited clinical significance. For this reason, the mean results were also reported, showing values of $800 \pm 220,210 \pm 30$, and $630 \pm 170$ days for group 1 , group 2 , and all patients, respectively. Similarly, the ranges were 373-1,219, 144-272, and 298-961 days. The log-rank analysis showed a statistically significant difference $(P=0.0035)$ in OST between groups 1 and 2, while no other pairwise multiple comparisons yielded significant differences. Similarly, the results for PFS are shown for each patient group separately and as a whole (Fig. 5). For groups 1 and 2, the median PFS was 780 and 160 days, respectively, while the value for the whole patient set was 220 days.

As for the OST, the mean PFS values were $500 \pm 140,150 \pm 18$, and $400 \pm 110$ days for group 1, group 2, and all the patients, respectively, while the 95\% confidence interval ranges were 234-783, 119-188, and 187-611 days, respectively. The log-rank analysis showed no statistically significant difference in PFS between any pairwise multiple comparisons. The OST rates for group 1 and all dogs that were kept together were 54\% and 38\%, respectively, at one year while no dogs were still alive from group 2. Similarly, the reported rates for local PFS were $58 \%$ and $40 \%$, respectively.

\section{DISCUSSION}

To the best of our knowledge, no combined chemotherapy and RT studies have been conducted in veterinary medicine with WPRT and MLSIB. This strategy could be an important factor for limiting local tumor progression and may improve the outlook for progression or death due to local disease; however, it could also limit tumor spread remotely via lymphatics first to the lymph nodes and then to the lungs, liver, and bones through the blood stream. In our study, almost all the plans fulfilled the prescribed target dose request, and a good agreement between the prescribed and delivered doses was revealed, demonstrating the treatment feasibility. The use of a dedicated cradle with a vacuum-locked bag and the LINAC XVI CBCT check, performed before each session, enabled a reproducible patient setup.

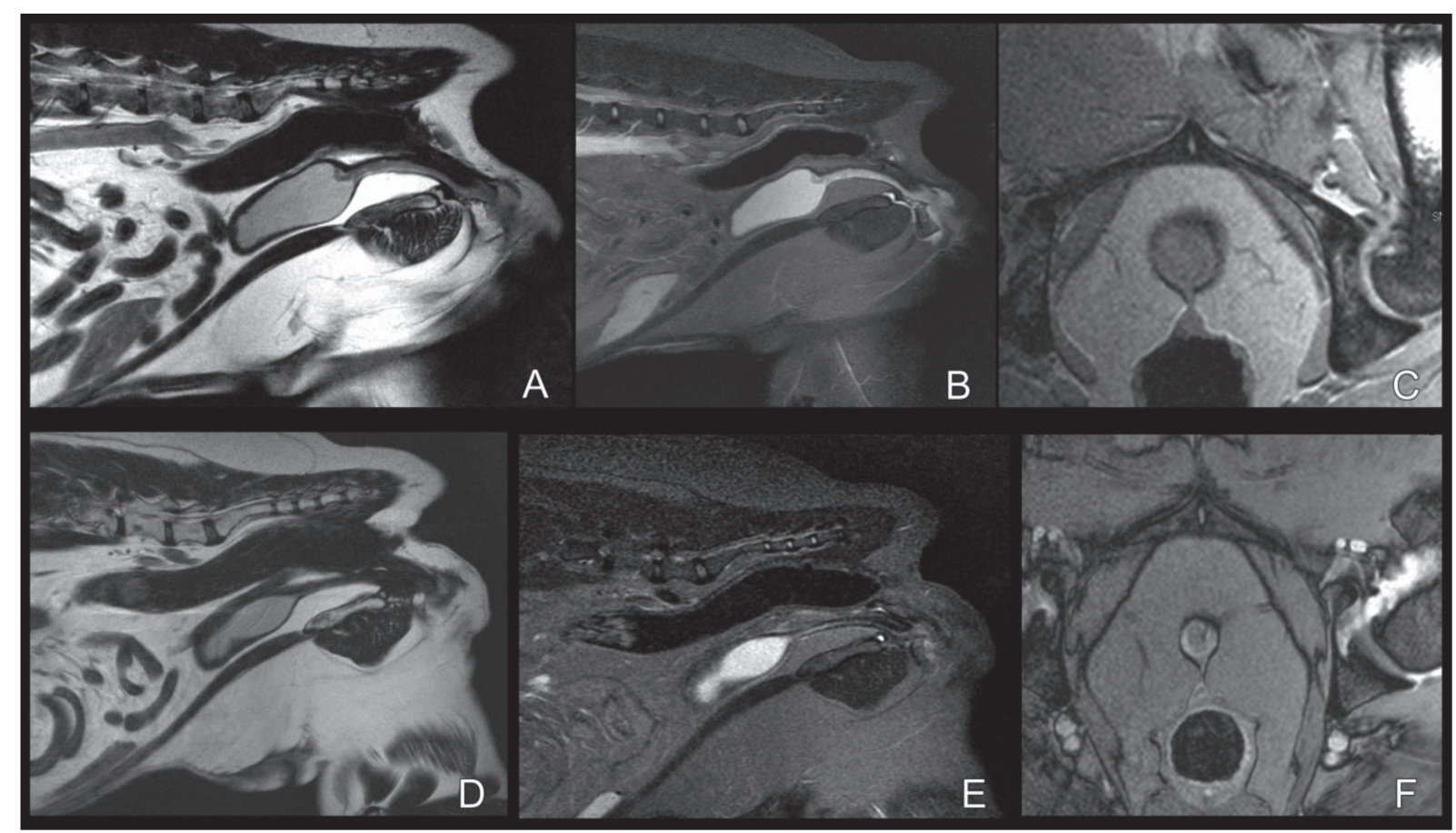

Fig. 3. Dog \#3, Transitional cell carcinoma of the urethra, MRI of the caudal abdomen and pelvis (A and D, sagittal Turbo Spin Eco (TSE) T2weighted; B and E, sagittal Short tau inversion recovery (STIR); C and F, axial contrast enhanced Fast Field Echo (FFE) T1-weighted at the level of the cranial urethra) at diagnosis (A, B, C) and two months after the end of the RT treatment (D, E, F), demonstrating complete response. 


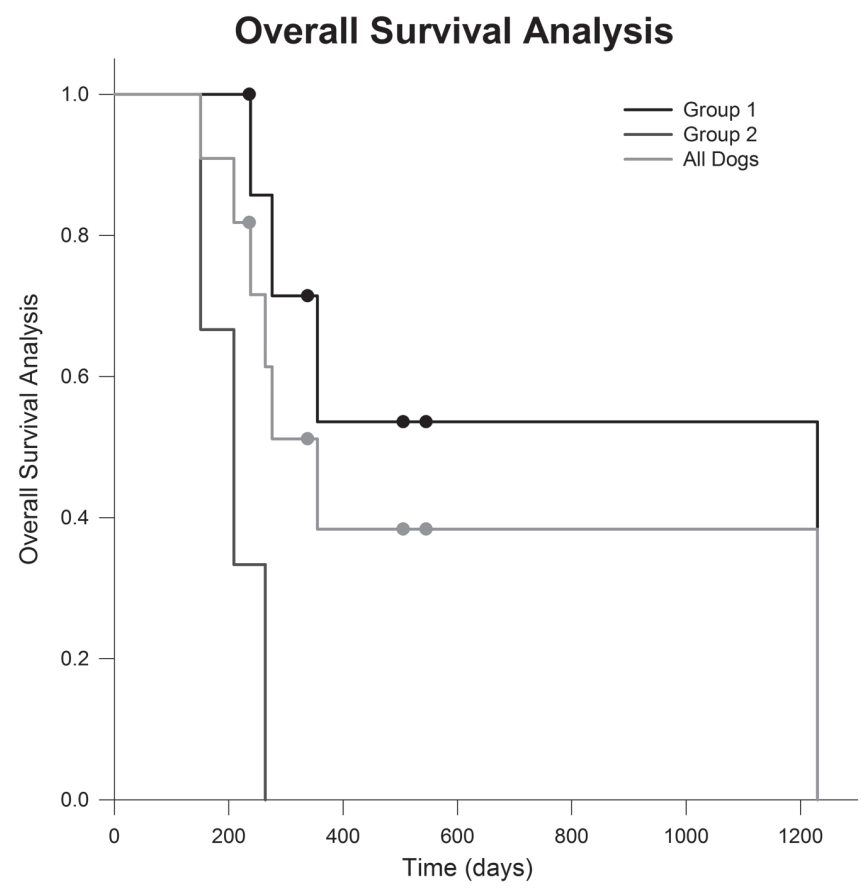

Fig. 4. Kaplan-Meier overall survival time analysis curve. In black, the 8 patients from group 1; in gray, the 4 patients from group 2; in light gray, all patients kept together.

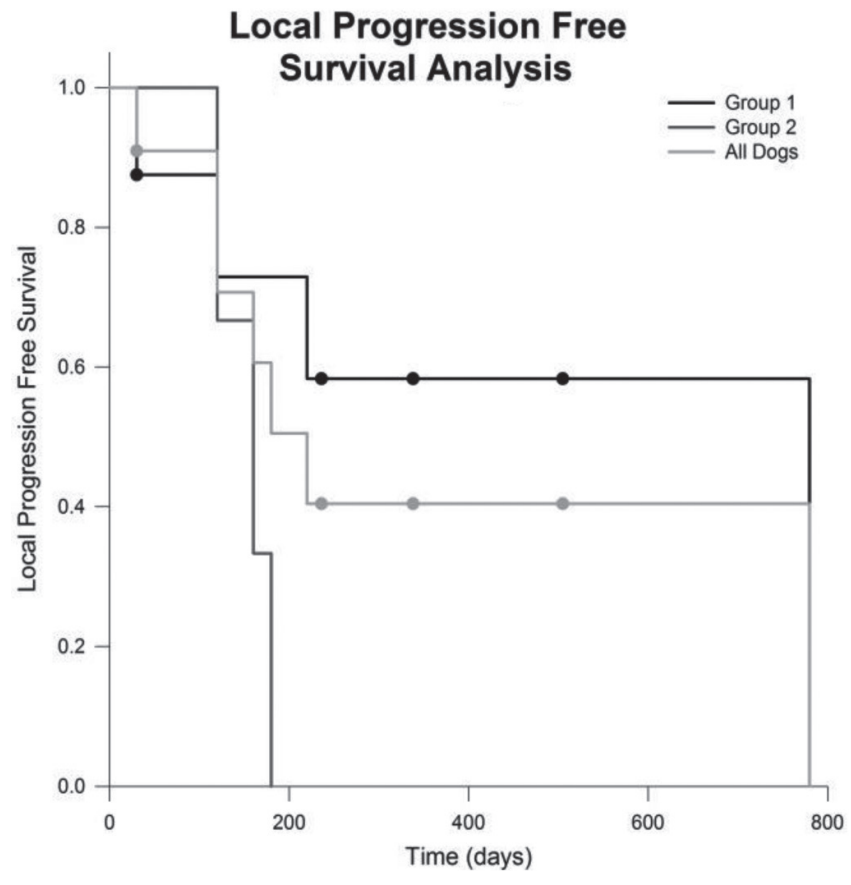

Fig. 5. Kaplan-Meier progression free survival time analysis curve. In black, the 8 patients from group 1; in gray, the 4 patients from group 2; in light gray, all patients kept together.

All dogs showed progressive shrinkage of the tumor during follow-up, and according to RECIST, four dogs had a CR, five dogs had a PR, one dog had SD, and one dog had PD. One patient was lost at the first follow-up, and the owner informed us of the animal's death at the subsequent interview.

A study of normal tissue complications in 51 dogs undergoing definitive pelvic region irradiation with $\mathrm{Co}^{60}$ gamma ray standard conformal radiotherapy [5] reported acute side effects, such as epithelial desquamation and mucositis, and late complications, such as chronic colitis/enteritis, gastrointestinal perforation, rectal/anal fistulas, strictures (urinary, rectal, and gastrointestinal), myelopathies, and bone necrosis. In another study [73], high single doses administered intraoperatively caused severe late radiation toxicity, resulting in euthanasia in up to $36 \%$ of dogs with TCC. According to the two previously cited studies, a fraction size $>3$ Gy with standard conformal 3D RT was associated with a high risk of late effects $[5,73]$. The dose prescription in our study was higher than the 3 Gy limit. Moreover, the WPRT with MLSIB was irradiated, but no clinical or radiological toxicity was observed. In particular, in some patients, VRTOG 1 level signs, such as pollakiuria, urinary incontinence, cystitis, and stranguria, with a duration of a few days were observed. No gastrointestinal complications were reported. Only one dog had proctitis with a duration of 3 days (VRTOG 1), and one dog presented with grade 1 late fibrosis.

In the study by Nolan et al. [56], 21 dogs with genitourinary carcinomas were irradiated with intensity-modulated and imageguided radiation therapy on the lymph nodes in addition to the primary tumor, but not in prophylactic treatment as in this study. In contrast, in our study, the rest of the bladder and/or urethra and the rest of the pelvis were irradiated in addition to the primary tumor and lymph nodes. The tumor dose in the study by Nolan et al. ranged from 54 to 58 Gy (while for the lymph nodes, doses ranged from 28 to $54 \mathrm{~Gy}$ ) delivered in 20 daily fractions, corresponding to an EQD2 range of 61.2 to 63.22 Gy considering the alpha/beta ratio of 3.27 reported for this pathology in the literature [59]; this was similar to the lower limit of our dose prescription $(63.3$ to $81.9 \mathrm{~Gy})$. The absence of severe side effects showed the safety of the protocol and could be related to the high conformity obtained using the VMAT technique, which permitted good target coverage while sparing the OAR, suggesting dose escalation trials with a possible improvement in tumor control probability (TCP).

Carboplatin $\left(25 \mathrm{mg} / \mathrm{m}^{2}\right)$ was used in our study as a radiosensitizer. Only six dogs received chemotherapy, also after the end of the RT course. This could have provided a further advantage, but this effect is yet to be determined. However, it is not possible to provide suggestions about the component of the multimodal approach that provides the main contribution to PFS. Moreover, additional therapy could have improved long-term outcomes. A combined radio-chemotherapy protocol was presented in a previous study [62], where in piroxicam and mitoxantrone were administered in combination with once-weekly course fraction radiation therapy (six weekly fractions of $5.75 \mathrm{~Gy}$ ) in $10 \mathrm{dogs}$. One dog experienced acute effects of radiation therapy (grade 1 dermatitis), and late side effects occurred in four dogs (cutaneous hyperpigmentation and urinary incontinence). Regarding survival, dogs in group 1 had a greater median OST (1,230 days) in comparison with the same value reported in the literature regarding various treatment modalities, but the high percentage of patients still alive at the time of writing this paper (50\% of group 1 and $33 \%$ of the whole patient set) led us to consider the mean OST value (800 days for group 1) as a more descriptive parameter than the median 
value, even if, with such a small sample, normal distribution cannot be confirmed and OST and PFS have small statistical meaning, having been evaluated mainly for a comparison with the reported literature. In this frame, by including the patients from group 2 with a pure palliative intent, the mean OST (600 days) result was comparable to that reported by other authors.

A recent study [15] reported that the median OST for canine TCC medically treated with COX inhibitors and/or systemic chemotherapy was 196 days. On multivariable analysis, TCC localization (hazard ratio [HR], 1.90; $P=0.037$ ), bone metastasis (HR, 2.76; $P=0.013$ ), and sternal lymphadenomegaly (HR, 3.56; $P=0.004$ ) were significantly associated with survival. Compared to the bladder localization, the urethral localization had higher metastasis rates to the bone $(6.3 \%$ versus $42.3 \% ; P=0.045)$ and lung (6.3\% versus $46.2 \% ; P=0.022)$. The survival time was shorter in the urethral localization than in the bladder localization (121.5 days versus 420 days; $P<0.001$ ). Other studies $[2,4,10,18,27,30,31,35,37-39,48,51,68]$ reported a median survival time ranging from 152 days to 323 days for COX inhibitors alone and from 147 days to 307 days for patients receiving a combination of chemotherapy and COX inhibitors.

In a study by Nolan et al. [56] based on intensity-modulated RT, a median OST of 654 days was reported, while in our study, the corresponding value was 1,230 days; moreover, 326 days were reported by Poirier [62] for a chemoradiotherapy combined treatment where the protocol was well tolerated, but the course fractionation therapy did not result in enhanced response rates compared to a previous study of dogs treated with mitoxantrone and piroxicam without radiotherapy [31]. Retrospective studies of a combination of chemotherapy protocols showed a median survival of 259 days with a combination of doxorubicin and cyclophosphamide treatment in 11 dogs [30] and 358 days with anthracycline and platinum drug combinations in 15 dogs [65]. Administration of cisplatin (60 $\left.\mathrm{mg} / \mathrm{m}^{2}\right)$ combined with piroxicam $(0.3 \mathrm{mg} / \mathrm{kg})$ produced the highest percentage of remission in dogs, but this combination caused renal toxicity, and a higher dose of cisplatin is not recommended [27]. Based on published data, the absolute survival benefit for chemotherapy-treated dogs was modest at best, strongly supporting the need for the development of more effective regimens.

Regarding surgery, Norris [57] reported a post-surgery median survival of 125 days in 23 dogs, and Helfand [30] reported 86 days in 14 dogs with TCC. However, most dogs with this disease are usually deemed unsuitable [31, 54] because of trigonal location or advanced tumor stage; only 2 dogs from our study qualified for surgical resection. Partial cystectomy was considered an option in dogs with apex or mid-body localization [51], with a PFS of 235 days and a median survival time of 348 days (772 days in dogs receiving daily piroxicam). Additionally, laser ablation combined with piroxicam and mitoxantrone was investigated [72], with median and mean progression-free intervals of 200 and 280 days, respectively, and median and mean overall survival times of 299 and 411 days, respectively. The median PFS reported in this study was 220 days considering all the dogs and 780 days and 160 days for group 1 and group 2, respectively, and the mean values were 400, 550, and 150 days, respectively, showing comparable local progression outcomes to the surgery-devoted papers. In addition, ultrasound-guided endoscopic diode laser ablation was tested for TCC of the lower urinary tract with palliative intent in $38 \mathrm{dogs}$ [14]. The median survival time was 380 days for tumors localized only to the urethra, 390 days for tumors in the urethra and trigone, and 473 days for tumors in the body or apex of the bladder, with no involvement of the trigone or urethra.

In conclusion, this study has shown that the adopted protocol is well tolerated, safe, and feasible. The efficacy should be investigated in larger cohort studies for a better comparison with patients undergoing different therapeutic approaches, even if the initial findings regarding both the OST and PFS indicate that the results relative to the local tumor control are at least comparable to those reported in the cited literature. Moreover, in metastatic dogs, a valuable improvement has been observed in both quality of life (with a return to urination in obstructed patients during RT treatment) and in local tumor control.

POTENTIAL CONFLICTS OF INTEREST. The authors have nothing to disclose.

\section{REFERENCES}

1. Abbo, A. H., Jones, D. R., Masters, A. R., Stewart, J. C., Fourez, L. and Knapp, D. W. 2010. Phase I clinical trial and pharmacokinetics of intravesical mitomycin $\mathrm{C}$ in dogs with localized transitional cell carcinoma of the urinary bladder. J. Vet. Intern. Med. 24: 1124-1130. [Medline] [CrossRef]

2. Allstadt, S. D., Rodriguez, C. O. Jr., Boostrom, B., Rebhun, R. B. and Skorupski, K. A. 2015. Randomized phase III trial of piroxicam in combination with mitoxantrone or carboplatin for first-line treatment of urogenital tract transitional cell carcinoma in dogs. J. Vet. Intern. Med. 29: $261-267$. [Medline] [CrossRef]

3. Anderson, C. R., McNiel, E. A., Gillette, E. L., Powers, B. E. and LaRue, S. M. 2002. Late complications of pelvic irradiation in 16 dogs. Vet. Radiol. Ultrasound 43: 187-192. [Medline] [CrossRef]

4. Arnold, E. J., Childress, M. O., Fourez, L. M., Tan, K. M., Stewart, J. C., Bonney, P. L. and Knapp, D. W. 2011. Clinical trial of vinblastine in dogs with transitional cell carcinoma of the urinary bladder. J. Vet. Intern. Med. 25: 1385-1390. [Medline] [CrossRef]

5. Arthur, J. J., Kleiter, M. M., Thrall, D. E. and Pruitt, A. F. 2008. Characterization of normal tissue complications in 51 dogs undergoing definitive pelvic region irradiation. Vet. Radiol. Ultrasound 49: 85-89. [Medline] [CrossRef]

6. Barentsz, J. O., Jager, G. J., Witjes, J. A. and Ruijs, J. H. 1996. Primary staging of urinary bladder carcinoma: the role of MRI and a comparison with CT. Eur. Radiol. 6: 129-133. [Medline] [CrossRef]

7. Begg, A. C., van der Kolk, P. J., Emondt, J. and Bartelink, H. 1987. Radiosensitization in vitro by cis-diammine (1,1-cyclobutanedicarboxylato) platinum(II) (carboplatin, JM8) and ethylenediammine-malonatoplatinum(II) (JM40). Radiother. Oncol. 9: 157-165. [Medline] [CrossRef]

8. Benedict, S. H., Yenice, K. M., Followill, D., Galvin, J. M., Hinson, W., Kavanagh, B., Keall, P., Lovelock, M., Meeks, S., Papiez, L., Purdie, T., Sadagopan, R., Schell, M. C., Salter, B., Schlesinger, D. J., Shiu, A. S., Solberg, T., Song, D. Y., Stieber, V., Timmerman, R., Tomé, W. A., Verellen, D., Wang, L. and Yin, F. F. 2010. Stereotactic body radiation therapy: the report of AAPM Task Group 101. Med. Phys. 37: 4078-4101. [Medline] [CrossRef]

9. Blackburn, A. L., Berent, A. C., Weisse, C. W. and Brown, D. C. 2013. Evaluation of outcome following urethral stent placement for the treatment of obstructive carcinoma of the urethra in dogs: 42 cases (2004-2008). J. Am. Vet. Med. Assoc. 242: 59-68. [Medline] [CrossRef] 
10. Boria, P. A., Glickman, N. W., Schmidt, B. R., Widmer, W. R., Mutsaers, A. J., Adams, L. G., Snyder, P. W., DiBernardi, L., de Gortari, A. E., Bonney, P. L. and Knapp, D. W. 2005. Carboplatin and piroxicam therapy in 31 dogs with transitional cell carcinoma of the urinary bladder. Vet. Comp. Oncol. 3: 73-80. [Medline] [CrossRef]

11. Boston, S. and Singh, A. 2014. Total cystectomy for treatment of transitional cell carcinoma of the urethra and bladder trigone in a dog. Vet. Surg. 43: 294-300. [Medline] [CrossRef]

12. Brady, L. W., Perez, C. A. and Halperin, E. C. 2008. Radiation Oncology, 5th ed., Lippincott, Philadelphia.

13. Burton, J. H., Mitchell, L., Thamm, D. H., Dow, S. W. and Biller, B. J. 2011. Low-dose cyclophosphamide selectively decreases regulatory T cells and inhibits angiogenesis in dogs with soft tissue sarcoma. J. Vet. Intern. Med. 25: 920-926. [Medline] [CrossRef]

14. Cerf, D. J. and Lindquist, E. C. 2012. Palliative ultrasound-guided endoscopic diode laser ablation of transitional cell carcinomas of the lower urinary tract in dogs. J. Am. Vet. Med. Assoc. 240: 51-60. [Medline] [CrossRef]

15. Chan, R. C., Bracken, R. B. and Johnson, D. E. 1979. Single dose whole pelvis megavoltage irradiation for palliative control of hematuria or ureteral obstruction. J. Urol. 122: 750-751. [Medline] [CrossRef]

16. Charney, V. A., Miller, M. A., Heng, H. G., Weng, H. Y. and Knapp, D. W. 2017. Skeletal metastasis of canine urothelial carcinoma: pathologic and computed tomographic features. Vet. Pathol. 54: 380-386. [Medline] [CrossRef]

17. Choi, L. M. R., Rood, B., Kamani, N., La Fond, D., Packer, R. J., Santi, M. R. and Macdonald, T. J. 2008. Feasibility of metronomic maintenance chemotherapy following high-dose chemotherapy for malignant central nervous system tumors. Pediatr. Blood Cancer 50: 970-975. [Medline] [CrossRef]

18. Chun, R., Knapp, D. W., Widmer, W. R., DeNicola, D. B., Glickman, N. W., Kuczek, T., Degortari, A. and Han, C. M. 1997. Phase II clinical trial of carboplatin in canine transitional cell carcinoma of the urinary bladder. J. Vet. Intern. Med. 11: 279-283. [Medline] [CrossRef]

19. Culp, W. T., Weisse, C., Berent, A. C., Reetz, J. A., Krick, E. L., Jackson, D. E., Kass, P. H., Clifford, C. A. and Sorenmo, K. U. 2015. Early tumor response to intraarterial or intravenous administration of carboplatin to treat naturally occurring lower urinary tract carcinoma in dogs. J. Vet. Intern. Med. 29: 900-907. [Medline] [CrossRef]

20. Di Lorenzo, G., Pagliuca, M., Perillo, T., Zarrella, A., Verde, A., De Placido, S. and Buonerba, C. 2016. Complete Response and Fatigue Improvement With the Combined Use of Cyclophosphamide and Quercetin in a Patient With Metastatic Bladder Cancer: A Case Report. Medicine (Baltimore) 95: e2598. [Medline] [CrossRef]

21. Dolera, M., Malfassi, L., Carrara, N., Finesso, S., Marcarini, S., Mazza, G., Pavesi, S., Sala, M. and Urso, G. 2018. Volumetric modulated arc (radio) therapy in pets treatment: the "la Cittadina Fondazione" experience. Cancers (Basel) 10: 30. [Medline] [CrossRef]

22. Eisenhauer, E. A., Therasse, P., Bogaerts, J., Schwartz, L. H., Sargent, D., Ford, R., Dancey, J., Arbuck, S., Gwyther, S., Mooney, M., Rubinstein, L., Shankar, L., Dodd, L., Kaplan, R., Lacombe, D. and Verweij, J. 2009. New response evaluation criteria in solid tumours: revised RECIST guideline (version 1.1). Eur. J. Cancer 45: 228-247. [Medline] [CrossRef]

23. Elmslie, R. E., Glawe, P. and Dow, S. W. 2008. Metronomic therapy with cyclophosphamide and piroxicam effectively delays tumor recurrence in dogs with incompletely resected soft tissue sarcomas. J. Vet. Intern. Med. 22: 1373-1379. [Medline] [CrossRef]

24. Fonseca-Alves, C. and Gouveia Calazans, S. 2016. Metronomic chemotherapy in small animal practice: an update. Asian J. Anim. Vet. Adv. 11: 17-23. [CrossRef]

25. Fosså, S. D. 1991. Pelvic palliation radiotherapy of advanced bladder cancer. Int. J. Radiat. Oncol. Biol. Phys. 20: 1379. [Medline] [CrossRef]

26. Fulkerson, C. M. and Knapp, D. W. 2015. Management of transitional cell carcinoma of the urinary bladder in dogs: a review. Vet. J. 205: 217-225. [Medline] [CrossRef]

27. Greene, S. N., Lucroy, M. D., Greenberg, C. B., Bonney, P. L. and Knapp, D. W. 2007. Evaluation of cisplatin administered with piroxicam in dogs with transitional cell carcinoma of the urinary bladder. J. Am. Vet. Med. Assoc. 231: 1056-1060. [Medline] [CrossRef]

28. Gustafson, T. L. and Biller, B. 2019. Use of toceranib phosphate in the treatment of canine bladder tumors: 37 cases. J. Am. Anim. Hosp. Assoc. 55: 243-248. [Medline] [CrossRef]

29. Hautmann, R. E., Gschwend, J. E., de Petriconi, R. C., Kron, M. and Volkmer, B. G. 2006. Cystectomy for transitional cell carcinoma of the bladder: results of a surgery only series in the neobladder era. J. Urol. 176: 486-492, discussion 491-492. [Medline] [CrossRef]

30. Helfand, S., Hamilton, T. and Hungerford, L. 1994. Comparison of three treatments for transitional cell carcinoma of the bladder in the dog. J. Am. Anim. Hosp. Assoc. 30: 270-275.

31. Henry, C. J., McCaw, D. L., Turnquist, S. E., Tyler, J. W., Bravo, L., Sheafor, S., Straw, R. C., Dernell, W. S., Madewell, B. R., Jorgensen, L., Scott, M. A., Higginbotham, M. L. and Chun, R. 2003. Clinical evaluation of mitoxantrone and piroxicam in a canine model of human invasive urinary bladder carcinoma. Clin. Cancer Res. 9: 906-911. [Medline]

32. Iwasaki, R., Shimosato, Y., Yoshikawa, R., Goto, S., Yoshida, K., Murakami, M., Kawabe, M., Sakai, H. and Mori, T. 2019. Survival analysis in dogs with urinary transitional cell carcinoma that underwent whole-body computed tomography at diagnosis. Vet. Comp. Oncol. 17: 385-393. [Medline] [CrossRef]

33. Kaplan, E. L. and Meier, P. 1958. Nonparametric estimation from incomplete observations. J. Am. Stat. Assoc. 53: 457-481. [CrossRef]

34. Knapp, D. W. and McMillan, S. K. 2013. Tumors of the urinary system. pp. 572-582. In: Withrow and MacEwen's Small Animal Clinical Oncology, 5th ed. (Withrow, S. J., Vail, D. M. and Page, R. L. eds.), Saunders Elsevier, St. Louis.

35. Knapp, D. W., Glickman, N. W., Denicola, D. B., Bonney, P. L., Lin, T. L. and Glickman, L. T. 2000. Naturally-occurring canine transitional cell carcinoma of the urinary bladder A relevant model of human invasive bladder cancer. Urol. Oncol. 5: 47-59. [Medline] [CrossRef]

36. Knapp, D. W., Ramos-Vara, J. A., Moore, G. E., Dhawan, D., Bonney, P. L. and Young, K. E. 2014. Urinary bladder cancer in dogs, a naturally occurring model for cancer biology and drug development. ILAR J. 55: 100-118. [Medline] [CrossRef]

37. Knapp, D. W., Ruple-Czerniak, A., Ramos-Vara, J. A., Naughton, J. F., Fulkerson, C. M. and Honkisz, S. I. 2016. A nonselective cyclooxygenase inhibitor enhances the activity of vinblastine in a naturally-occurring canine model of invasive urothelial carcinoma. Bladder Cancer 2: 241-250. [Medline] [CrossRef]

38. Knapp, D. W., Richardson, R. C., Chan, T. C., Bottoms, G. D., Widmer, W. R., DeNicola, D. B., Teclaw, R., Bonney, P. L. and Kuczek, T. 1994. Piroxicam therapy in 34 dogs with transitional cell carcinoma of the urinary bladder. J. Vet. Intern. Med. 8: 273-278. [Medline] [CrossRef]

39. Knapp, D. W., Henry, C. J., Widmer, W. R., Tan, K. M., Moore, G. E., Ramos-Vara, J. A., Lucroy, M. D., Greenberg, C. B., Greene, S. N., Abbo, A. H., Hanson, P. D., Alva, R. and Bonney, P. L. 2013. Randomized trial of cisplatin versus firocoxib versus cisplatin/firocoxib in dogs with transitional cell carcinoma of the urinary bladder. J. Vet. Intern. Med. 27: 126-133. [Medline] [CrossRef]

40. Ladue, T. and Klein, M. K. Veterinary Radiation Therapy Oncology Group 2001. Toxicity criteria of the veterinary radiation therapy oncology group. Vet. Radiol. Ultrasound 42: 475-476. [Medline] [CrossRef]

41. Lawrence, J. A. and Saba, C. F. 2012. Tumors of the male reproductive system. In: Withrow and MacEwen's Small Animal Clinical Oncology, 5th ed. Elsevier, New York.

42. Lee, K., Choi, S., Choi, H. and Lee, Y. 2016. Clinical experience of MRI in two dogs with muscle-invasive transitional cell carcinoma of the urinary bladder. J. Vet. Med. Sci. 78: 1351-1354. [Medline] [CrossRef] 
43. Liptak, J. M., Brutscher, S. P., Monnet, E., Dernell, W. S., Twedt, D. C., Kazmierski, K. J., Walter, C. U., Mullins, M. N., Larue, S. M. and Withrow, S. J. 2004. Transurethral resection in the management of urethral and prostatic neoplasia in 6 dogs. Vet. Surg. 33: 505-516. [Medline] [CrossRef]

44. López-Aguilar, E., Sepúlveda-Vildósola, A. C., Betanzos-Cabrera, Y., Rocha-Moreno, Y. G., Gascón-Lastiri, G., Rivera-Márquez, H., Wanzke-delAngel, V., Cerecedo-Díaz, F. and de la Cruz-Yañez, H. 2008. Phase II study of metronomic chemotherapy with thalidomide, carboplatin-vincristinefluvastatin in the treatment of brain stem tumors in children. Arch. Med. Res. 39: 655-662. [Medline] [CrossRef]

45. Low, D. A. and Dempsey, J. F. 2003. Evaluation of the gamma dose distribution comparison method. Med. Phys. 30: 2455-2464. [Medline] [CrossRef]

46. Mahmud, F., Chung, S. W., Alam, F., Choi, J. U., Kim, S. W., Kim, I. S., Kim, S. Y., Lee, D. S. and Byun, Y. 2017. Metronomic chemotherapy using orally active carboplatin/deoxycholate complex to maintain drug concentration within a tolerable range for effective cancer management. J. Control. Release 249: 42-52. [Medline] [CrossRef]

47. Marchetti, V., Giorgi, M., Fioravanti, A., Finotello, R., Citi, S., Canu, B., Orlandi, P., Di Desidero, T., Danesi, R. and Bocci, G. 2012. First-line metronomic chemotherapy in a metastatic model of spontaneous canine tumours: a pilot study. Invest. New Drugs 30: 1725-1730. [Medline] [CrossRef]

48. Marconato, L., Nitzl, D. B., Melzer-Ruess, K. J., Keller, M. A. and Buchholz, J. 2012. Chemotherapy and radiation therapy in 4 dogs with muscleinvasive transitional cell carcinoma of the urinary tract. Can. Vet. J. 53: 875-879. [Medline]

49. Marconato, L., Zini, E., Lindner, D., Suslak-Brown, L., Nelson, V. and Jeglum, A. K. 2011. Toxic effects and antitumor response of gemcitabine in combination with piroxicam treatment in dogs with transitional cell carcinoma of the urinary bladder. J. Am. Vet. Med. Assoc. 238: 1004-1010. [Medline] [CrossRef]

50. Marvel, S. J., Séguin, B., Dailey, D. D. and Thamm, D. H. 2017. Clinical outcome of partial cystectomy for transitional cell carcinoma of the canine bladder. Vet. Comp. Oncol. 15: 1417-1427. [Medline] [CrossRef]

51. McMillan, S. K., Boria, P., Moore, G. E., Widmer, W. R., Bonney, P. L. and Knapp, D. W. 2011. Antitumor effects of deracoxib treatment in 26 dogs with transitional cell carcinoma of the urinary bladder. J. Am. Vet. Med. Assoc. 239: 1084-1089. [Medline] [CrossRef]

52. McMillan, S. K., Knapp, D. W., Ramos-Vara, J. A., Bonney, P. L. and Adams, L. G. 2012. Outcome of urethral stent placement for management of urethral obstruction secondary to transitional cell carcinoma in dogs: 19 cases (2007-2010). J. Am. Vet. Med. Assoc. 241: 1627-1632. [Medline] [CrossRef]

53. Murphy, S., Gutiérrez, A., Lawrence, J., Bjorling, D., Mackie, T. and Forrest, L. 2008. Laparoscopically implanted tissue expander radiotherapy in canine transitional cell carcinoma. Vet. Radiol. Ultrasound 49: 400-405. [Medline] [CrossRef]

54. Mutsaers, A. J., Widmer, W. R. and Knapp, D. W. 2003. Canine transitional cell carcinoma. J. Vet. Intern. Med. 17: 136-144. [Medline] [CrossRef]

55. Nieset, J. R., Harmon, J. F., Johnson, T. E. and Larue, S. M. 2014. Comparison of adaptive radiotherapy techniques for external radiation therapy of canine bladder cancer. Vet. Radiol. Ultrasound 55: 644-650. [Medline] [CrossRef]

56. Nolan, M. W., Kogan, L., Griffin, L. R., Custis, J. T., Harmon, J. F., Biller, B. J. and Larue, S. M. 2012. Intensity-modulated and image-guided radiation therapy for treatment of genitourinary carcinomas in dogs. J. Vet. Intern. Med. 26: 987-995. [Medline] [CrossRef]

57. Norris, A. M., Laing, E. J., Valli, V. E., Withrow, S. J., Macy, D. W., Ogilvie, G. K., Tomlinson, J., McCaw, D., Pidgeon, G. and Jacobs, R. M. 1992. Canine bladder and urethral tumors: a retrospective study of 115 cases (1980-1985). J. Vet. Intern. Med. 6: 145-153. [Medline] [CrossRef]

58. Palladino, S., Keyerleber, M. A., King, R. G. and Burgess, K. E. 2016. Utility of computed tomography versus abdominal ultrasound examination to identify iliosacrallymphadenomegaly in dogs with apocrine gland adenocarcinoma of the anal sac. J. Vet. Intern. Med. 30: 1858-1863. [Medline] [CrossRef]

59. Parfitt, S. L., Milner, R. J., Salute, M. E., Hintenlang, D. E., Farese, J. P., Bacon, N. J., Bova, F. J., Rajon, D. A. and Lurie, D. M. 2011. Radiosensitivity and capacity for radiation-induced sublethal damage repair of canine transitional cell carcinoma (TCC) cell lines. Vet. Comp. Oncol. 9: 232-240. [Medline] [CrossRef]

60. Patrick, D. J., Fitzgerald, S. D., Sesterhenn, I. A., Davis, C. J. and Kiupel, M. 2006. Classification of canine urinary bladder urothelial tumours based on the World Health Organization/International Society of Urological Pathology consensus classification. J. Comp. Pathol. 135: 190-199. [Medline] [CrossRef]

61. Penninck, D. and D'Anjou, M. 2015. Atlas of Small Animal Ultrasonography, 2nd ed., Wiley-Blackwell, Ames.

62. Poirier, V. J., Forrest, L. J., Adams, W. M. and Vail, D. M. 2004. Piroxicam, mitoxantrone, and coarse fraction radiotherapy for the treatment of transitional cell carcinoma of the bladder in 10 dogs: a pilot study. J. Am. Anim. Hosp. Assoc. 40: 131-136. [Medline] [CrossRef]

63. Pollard, R. E., Fuller, M. C. and Steffey, M. A. 2017. Ultrasound and computed tomography of the iliosacral lymphatic centre in dogs with anal sac gland carcinoma. Vet. Comp. Oncol. 15: 299-306. [Medline] [CrossRef]

64. Rippy, S. B., Gardner, H. L., Nguyen, S. M., Warry, E. E., Portela, R. A., Drost, W. T., Hostnik, E. T., Green, E. M., Chew, D. J., Peng, J. and London, C. A. 2016. A pilot study of toceranib/vinblastine therapy for canine transitional cell carcinoma. BMC Vet. Res. 12: 257. [Medline] [CrossRef]

65. Rocha, T. A., Mauldin, G. N., Patnaik, A. K. and Bergman, P. J. 2000. Prognostic factors in dogs with urinary bladder carcinoma. J. Vet. Intern. Med. 14: 486-490. [Medline] [CrossRef]

66. Saeki, K., Fujita, A., Fujita, N., Nakagawa, T. and Nishimura, R. 2015. Total cystectomy and subsequent urinary diversion to the prepuce or vagina in dogs with transitional cell carcinoma of the trigone area: a report of 10 cases (2005-2011). Can. Vet. J. 56: 73-80. [Medline]

67. Saulnier-Troff, F. G., Busoni, V. and Hamaide, A. 2008. A technique for resection of invasive tumors involving the trigone area of the bladder in dogs: preliminary results in two dogs. Vet. Surg. 37: 427-437. [Medline] [CrossRef]

68. Schrempp, D. R., Childress, M. O., Stewart, J. C., Leach, T. N., Tan, K. M., Abbo, A. H., de Gortari, A. E., Bonney, P. L. and Knapp, D. W. 2013. Metronomic administration of chlorambucil for treatment of dogs with urinary bladder transitional cell carcinoma. J. Am. Vet. Med. Assoc. 242: 1534-1538. [Medline] [CrossRef]

69. Simsek, C., Esin, E. and Yalcin, S. 2019. Metronomic chemotherapy: a systematic review of the literature and clinical experience. J. Oncol. 2019: 5483791. [Medline] [CrossRef]

70. Skinner, O. T., Boston, S. E. and Maxwell, P. L. 2020. Interventions and experience after complicated total cystectomy in a dog with transitional cell carcinoma. Vet. Surg. 49: 811-817. [Medline] [CrossRef]

71. Stone, E. A., George, T. F., Gilson, S. D. and Page, R. L. 1996. Partial cystectomy for urinary bladder neoplasia: surgical technique and outcome in 11 dogs. J. Small Anim. Pract. 37: 480-485. [Medline] [CrossRef]

72. Upton, M. L., Tangner, C. H. and Payton, M. E. 2006. Evaluation of carbon dioxide laser ablation combined with mitoxantrone and piroxicam treatment in dogs with transitional cell carcinoma. J. Am. Vet. Med. Assoc. 228: 549-552. [Medline] [CrossRef]

73. Walker, M. and Breider, M. 1987. Intraoperative radiotherapy of canine bladder cancer. Vet. Radiol 28: 200-204. [CrossRef]

74. Weisse, C., Berent, A., Todd, K., Clifford, C. and Solomon, J. 2006. Evaluation of palliative stenting for management of malignant urethral obstructions in dogs. J. Am. Vet. Med. Assoc. 229: 226-234. [Medline] [CrossRef]

75. Withrow, S., Vail, D. and Page, R. 2014. Withrow and MacEwen's Small Animal Clinical Oncology, 5th ed., Elsevier, St. Louis.

76. Wongsetthachai, P., Pramatwinai, C., Banlunara, W. and Kalpravidh, M. 2011. Urinary bladder wall substitution using autologous tunica vaginalis in male dogs. Res. Vet. Sci. 90: 156-159. [Medline] [CrossRef]

77. Zhang, Y., Frimberger, D., Cheng, E. Y., Lin, H. K. and Kropp, B. P. 2006. Challenges in a larger bladder replacement with cell-seeded and unseeded small intestinal submucosa grafts in a subtotal cystectomy model. BJU Int. 98: 1100-1105. [Medline] [CrossRef] 